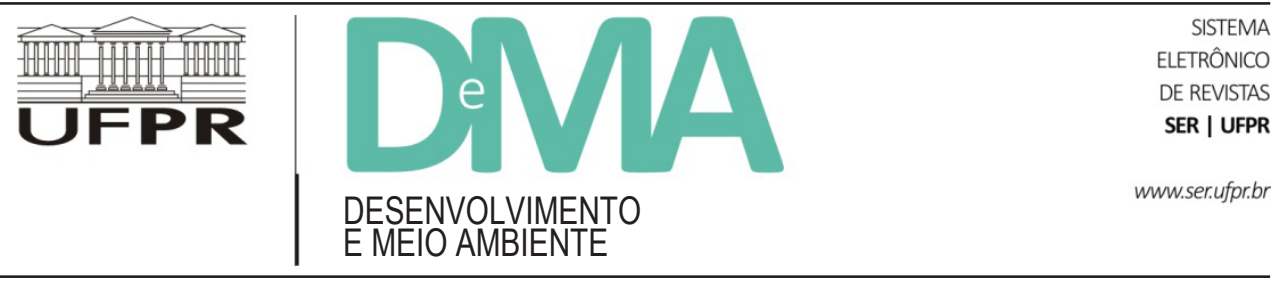

\title{
Produção científica e princípios da Educação em Agroecologia
}

\section{Scientific production and principles of Education in Agroecology}

\author{
Franklin Vieira COSTA ${ }^{1 *}$, Jorge Luis Cavalcanti RAMOS ${ }^{1}$, Denes Dantas VIEIRA ${ }^{1}$ \\ ${ }^{1}$ Universidade Federal do Vale do São Francisco (UNIVASF), Petrolina, PE, Brasil \\ *E-mail de contato: franklinvcosta@yahoo.com.br
}

Artigo recebido em 14 de abril de 2020, versão final aceita em 30 de outubro de 2020, publicado em 18 de dezembro de 2020.

RESUMO: Neste artigo foi feita uma análise da produção científica do II Seminário Nacional de Educação em Agroecologia (SNEA) e suas relações com os princípios da Educação em Agroecologia disseminados pela Associação Brasileira de Agroecologia (ABA). O evento foi realizado em 2016, no Colégio Técnico da Universidade Federal Rural do Rio de Janeiro (CTUR/UFRRJ), município de Seropédica/RJ. O procedimento técnico utilizado foi a pesquisa bibliográfica, a partir dos artigos referentes aos anais do II SNEA, publicados na Revista Cadernos de Agroecologia, no diálogo com os princípios e diretrizes da Educação em Agroecologia. No I Seminário Nacional de Educação em Agroecologia (SNEA) foram estabelecidos quatro princípios e diretrizes fundamentais para a Educação em Agroecologia: Princípio da Vida, Princípio da Complexidade, Princípio da Diversidade e Princípio da Transformação. O II SNEA promoveu reflexões e debates envolvendo Educação em Agroecologia, articulados a partir de eixos temáticos sobre a construção do conhecimento agroecológico, a formação do profissional em agroecologia e a questão agrária e agroecologia. Estas experiências são fruto do acúmulo histórico protagonizado por educadores/as, estudantes e pelos movimentos sociais do campo.

Palavras-chave: educação em agroecologia; conhecimento agroecológico; gênero.

ABSTRACT: In this article, an analysis was made of the scientific production of the II National Seminar on Education in Agroecology (SNEA), and its relations with the principles of Education in Agroecology, disseminated by the Brazilian Association of Agroecology (ABA). The event was held in 2016, at the Technical College of the Federal Rural University of Rio de Janeiro (CTUR / UFRRJ), municipality of Seropédica / RJ. The technical procedure used was Bibliographic Research, based on the articles referring to the annals of the II SNEA, published on Revista Cadernos de Agroecologia, conversing with the principles and guidelines of Education in 
Agroecology. At the 1st National Seminar on Education in Agroecology (SNEA), four fundamental principles and guidelines for Education in Agroecology were established: Life Principle, Complexity Principle, Diversity Principle and Transformation Principle. The II SNEA promoted reflections and debates involving Education in Agroecology, articulated from thematic axis on the construction of agroecological knowledge, the training of professionals in agroecology and the agrarian and agroecology issue. These experiences are the result of the historical data accumulation led by educators, students and social movements in the countryside.

Keywords: education in agroecology; agroecological knowledge; genre.

\section{Introdução}

A Educação em Agroecologia está fundamentada em referências da Educação do Campo e da Agroecologia (Cotrim \& Dal Soglio, 2016, p. 252). Para Petersen (2012, p. 69), essas duas grandes áreas do conhecimento fornecem os elementos estruturantes para a compreensão da educação com o enfoque agroecológico e seus desafios como projeto pedagógico e político na formação dos indivíduos. Muitos desses fundamentos estão inteiramente associados, em uma dinâmica de complementaridade e interdependência.

Os debates agroecológicos partem das externalidades produzidas pela Revolução Verde, em 1950 (Almeida et al., 2001). Segundo Caporal (2008, p. 913), as práticas e tecnologias implementadas por esse movimento agrícola levaram a uma crise socioambiental sem precedentes na história. Assim, toda a abordagem agroecológica nasce como contraponto à concentração tecnológica, à produção mecanicista, à monocultura e à concentração de renda, produtos da Revolução Verde, ao machismo, racismo, etc. Desta forma, a agroecologia se posiciona, principalmente, por meio de bandeiras ecológicas e sociais.

Outra base importante é a ruptura com o paradigma científico e a predominância do carte- sianismo. "O pensamento disciplinar não dá conta do estudo de fenômenos complexos, pois é incapaz de reconhecer e apreender a complexidade do real" (Morin, 2008, p. 52), as interações que ocorrem simultaneamente no agroecossistema e que com a inclusão de xenobióticos as interações se intensificam em prol de manter a vida e que isso desencadeia reações jamais previstas. A interdisciplinaridade e a troca de saberes são pressupostos indispensáveis à Educação em Agroecologia (Cotrim \& Dal Soglio, 2016, p. 255). São as inter-relações entre diversos campos de conhecimento que são capazes de produzir respostas para os desafios enfrentados nesse processo formativo (Cotrim \& Dal Soglio, 2016, p. 255).

Por isso, Morin (2005, p. 210) acredita que um estado de inter-relação e interdependência é essencial em todos os fenômenos; desta forma, a análise sistêmica se apresenta como um novo paradigma. A visão holística é uma das bases para a construção do conhecimento agroecológico e uma das saídas que responde às questões ecológicas, sociais, culturais, políticas e econômicas imersas na realidade do campo.

A fuga dessas "caixinhas" disciplinares também está relacionada ao diálogo dos saberes, onde o conhecimento popular é tão importante quanto o acadêmico/científico. "O conhecimento 
contextualizado é localizado e retoma o conceito de novidade como sendo um novo insight de uma prática ou mesmo uma nova prática" (Cotrim \& Dal Soglio, 2016, p. 260). A sabedoria popular emerge dos povos tradicionais e aponta soluções para uma coexistência socioambiental, que produz riqueza/valores mediante diversificação, seja de biodiversidade, seja de saberes, que por sua vez são desvalorizados pelos mecanismos autoritários e segregadores do capitalismo.

A perspectiva holística, alicerçada no diálogo dos saberes, necessita de métodos participativos para a construção do conhecimento e o fortalecimento da Educação em Agroecologia. "O método participativo é formado pelas ferramentas e técnicas participativas que se caracterizam pelas premissas de facilitarem ou organizarem o diálogo, o debate, e a troca entre os atores dentro da arena de construção de projetos sociais" (Cotrim \& Dal Soglio, 2016, p. 265). Desta forma, a construção coletiva é um subsídio fundamental para a efetivação de uma educação agroecológica.

A Educação em Agroecologia deve estar fincada na proposição da Educação Popular, de construção coletiva do conhecimento sobre a trajetória humana, sua cultura e as implicações para as lutas sociais populares (Machado, 2014, p. 223). Para tanto, a organicidade, a partilha da convivência com a construção do conhecimento, deve ser sistematizada, planejada e organizada coletivamente (Duarte \& Rabelo, 2016, p. 14).

Práxis e teoria devem estar articuladas para propiciar aos educandos a problematização da sua realidade, aprofundando os conhecimentos científicos e populares para a proposição de soluções. É necessária, mobilizando docentes, educandos, movimentos sociais e camponeses, para superação das dificuldades enfrentadas no campo (Molina et al., 2014, p. 246). A teoria vinculada à prática é um fundamento da Educação Popular, do Campo e Agroecológica.

Diante deste cenário, consolida-se na década de 1970 a agroecologia como ciência em contraposição aos problemas gerados por este modelo de agricultura (Gliessman, 2005, p. 385). Na sua construção como ciência, a agroecologia relaciona características multidisciplinares e relações complexas, inclusive com a incorporação do conhecimento tradicional, validado por metodologias científicas, na maioria das vezes por meio de métodos não convencionais e participativos (Menegueli et al., 2015, p. 36).

A agroecologia é uma ciência dialética mais do que um conceito ${ }^{1}$, transforma a agricultura vigente, muda a estrutura fundiária e o modelo agroquímico para uma posse da terra mais equânime e de produção de base ecológica. É axiomática a construção de um projeto estratégico para o campo brasileiro, a partir dos camponeses e numa direção mais racional para a produção de alimentos limpos. Os camponeses serão os sujeitos do processo. São eles quem estão dia a dia na prática de atividades do processo produtivo incorporando novo saberes (Cooperfumos, 2009, p. 24).

Para Carvalho (2010, p. 07), os(as) camponeses(as) são sujeitos da história na afirmação

\footnotetext{
${ }^{1}$ Conforme o Dicionário da Educação do Campo, o uso do termo agroecologia se popularizou nos anos de 1980, a partir dos trabalhos de Miguel Altieri e, posteriormente, de Stephen Gliessman, ambos pesquisadores de universidades estadunidenses e atualmente considerados os principais expoentes da "vertente americana” da agroecologia (Guhur \& Toná, 2012, p. 59).
} 
e ressignificação de identidades, a partir de um conjunto de elementos que demarcam o sentimento de pertencimento dos sujeitos que nele habitam e constroem seu modo de vida a partir das relações que estabelecem com os meios natural e social, na resistência popular das famílias camponesas, na cooperação agrícola, na integração de tecnologias que respeitem a natureza, no cuidado com as sementes, na diversificação da produção de alimentos e de um projeto de educação do campo vinculado a uma proposta popular, suas bandeiras de luta e sua construção.

A Agroecologia é aqui entendida como a ciência transdisciplinar que utiliza conceitos e princípios ecológicos no desenho e no manejo de agroecossistemas sustentáveis, proporcionando as ferramentas teóricas e práticas necessárias para a transição da agricultura convencional para outra mais ecológica e menos impactante, passando pelo redesenho dos agroecossistemas de modo que os mesmos alcancem seu equilíbrio dinâmico (Altieri, 2002, p. 358; Gliessman, 2009, p. 452; Sevilla Guzmán, 2013, p. 98).

Segundo Guzmán Casado et al. (2000, p. 21), a Agroecologia é vista em seu sentido mais amplo como uma matriz tecnológica que requer, ao menos, a articulação de três componentes básicos: o técnico-agronômico, modelado desde uma perspectiva ecológica; o sociocultural, contemplado desde uma perspectiva histórica; e o político, construído por meio do projeto de busca da igualdade.

Sua estratégia tem uma natureza sistêmica, ao considerar a propriedade rural, a organização comunitária e os demais marcos de relações sociais rurais, articulados em torno da dimensão local, na qual se encontram os sistemas de conhecimento portadores do potencial endógeno que permite potencializar a biodiversidade ecológica e sociocultural (Gliessman, 2009, p. 512).

A Agroecologia, segundo Leff (2001, p. 43), é um novo paradigma produtivo, uma constelação de ciências, técnicas e práticas para uma produção ecologicamente sustentável no campo. Esta nova perspectiva técnico-científica vem como uma nova forma de desenvolvimento rural, resgatando o saber popular, com um olhar holístico sobre as unidades agrícolas, buscando, por meio da ciência, da prática e da organização das comunidades rurais, desenvolverem ações alternativas para os agricultores alcançarem a independência, propondo novos meios de produção que gerem renda satisfatória e qualidade de vida.

Lacey (2006, p. 198) apresenta uma reflexão sobre a pesquisa agroecológica, ao afirmar que, se a mesma estivesse sob as mesmas condições materiais e sociais necessárias para explorar de maneira plena e sistematicamente as possibilidades de produção da safra servindo ao bem-estar local, e sendo bem-sucedida, isso seria uma ameaça ao avanço e à dominação do agronegócio e desafiaria também algumas das pressuposições da "globalização". O autor também afirma que o conhecimento científico é um dos bens comuns da humanidade, podendo esse conhecimento ser usado, mais ou menos de forma equitativa, em projetos moldados por interesses que incorporam quaisquer valores éticos/sociais/ culturais viáveis (Lacey, 2012, p. 439).

Segundo Petersen (2012, p. 68), a troca de saberes agrega o conhecimento popular ancestral e o empoderamento torna os agricultores ativos dentro de seu papel na sociedade. Na saúde, o poder nutricional das plantas é valorizado nos sistemas agroecológicos (Petersen, 2012, p. 70). Estes três pilares afirmam o potencial da agroecologia apli- 
cada nas dimensões sociais, econômicas e culturais (Petersen, 2012, p. 72). Partindo da premissa dos pilares da agroecologia, a construção deste saber deve ser baseada no conjunto de experiências de todos os atores envolvidos com a construção do saber. "Dentro deste processo, a agricultura de base ecológica tem se convertido em uma via utilizada por agricultores familiares para fazer frente à exclusão econômica e social e à deterioração ambiental, utilizando-se distintas formas associativas" (Costabeber \& Moyano, 2000, p. 50).

A agroecologia tem especificidades que referenciam a construção de outro projeto de campo. Entretanto, tal projeto de campo é incompatível com o modelo de desenvolvimento capitalista hegemônico vigente atualmente no Brasil e depende, em última instância, de sua superação (Almeida, 2013, p. 14). Neste sentido, está em gestação a concepção mais recente de agroecologia, ainda mais ampliada: a partir da prática dos movimentos sociais populares do campo, que não a entendem como "a" saída tecnológica para as crises estruturais e conjunturais do modelo econômico e agrícola, mas que a percebem como parte de sua estratégia de luta e de enfrentamento ao agronegócio e ao sistema capitalista de exploração dos trabalhadores e da depredação da natureza (Guhur \& Toná, 2012, p. 62).

\section{Metodologia}

O trabalho utiliza pesquisa bibliográfica desenvolvida por meio de material já publicado, de acesso público, disponível no portal eletrônico da Associação Brasileira de Agroecologia. Para Gil (2008, p. 50), “a principal vantagem da pesquisa bibliográfica reside no fato de permitir ao investiga- dor a cobertura de uma gama de fenômenos muito mais ampla do que aquela que poderia pesquisar diretamente".

Uma forma de analisar as informações qualitativas é utilizar a ferramenta de análise de conteúdo. Ela é um conjunto de técnicas de análise de comunicações que se relacionam com campos de análise de domínio linguístico, métodos lógicos estéticos e formais, métodos lógicos semânticos, métodos semânticos, estruturais e hermenêutica (Bardin, 2004, p. 63). Com essa ferramenta de análise, foram estruturados procedimentos sistemáticos e objetivos de exposição do conteúdo dos artigos, permitindo, dessa forma, a inferência de conhecimentos sobre os documentos avaliados.

Segundo Bardin (2004, p. 72), a técnica da análise de conteúdo se caracteriza por possuir três etapas: pré-análise, exploração do material e tratamento e interpretação dos resultados.

A primeira fase, pré-análise, consiste na sistematização das ideias iniciais estabelecidas no referencial teórico e no material coletado para pesquisa; essas ações estão vinculadas a uma leitura flutuante, à escolha de documentos, à formulação de hipóteses e objetivos e à elaboração de indicadores.

Neste estudo, a pré-análise ocorreu a partir da leitura de todos os resumos dos artigos do II SNEA e, a partir daí, foi feita uma primeira categorização e o enquadramento inicial dos trabalhos, para melhor direcionar as etapas seguintes. Nesta fase, a dificuldade (ou o principal obstáculo) foi o extenso número de trabalhos e a diversidade de temas abordados.

$\mathrm{Na}$ fase segunda do método, exploração do material, é o momento em que acontecem os recortes do texto, a codificação, a categorização e a classificação das informações, vinculando-se aos indicadores propostos e às teorias relacionadas ao 
estudo. Não existe uma fórmula padronizada para a construção das categorias, devendo estar sintonizadas à pesquisa, aos objetivos propostos nela e com o olhar do pesquisador.

Esta etapa se deu com a leitura detalhada de cada artigo, realizando sua correta classificação, destacando pontos importantes que reforçassem essa categorização. Nesta fase também ocorreu a necessidade de releitura de artigos já analisados, em função da necessidade de reenquadramento ou de inclusão do mesmo em outras categorias ou subcategorias, por conta de trabalhos similares que iam sendo analisados. A dificuldade encontrada foi também pela quantidade de trabalhos, exigindo dos autores um rigoroso trabalho de identificação de suas principais características.

A última fase é o momento do tratamento dos resultados, da inferência e da interpretação. A análise comparativa é realizada por meio da justaposição das diversas categorias existentes em cada análise, ressaltando os aspectos considerados semelhantes e os que foram concebidos como diferentes. A técnica de análise de conteúdo se utiliza de aspectos quantitativos, como frequências e percentuais para seus resultados, mas propicia, também, largas possibilidades para uma análise qualitativa consistente.

Nesta fase foi feita a enumeração dos indicadores pela contagem das unidades de registro, que, para esse caso, foram palavras encontradas nos artigos, em contextos específicos. Com auxílio do referencial teórico, foi detectada a presença de duas ou três subcategorias, em cada artigo analisado. A complementariedade dos princípios agroecológicos foi decisiva para que em um mesmo artigo fossem encontradas múltiplas diretrizes do campo da agroecologia.

Os dados foram tabulados em planilhas do programa Microsoft Office Excel, versão 2013. A partir dessas informações eletrônicas, foram gerados gráficos que serviram de suporte para a análise de resultados qualitativos deste trabalho. As avaliações qualitativas partiram desses números capturados e do encontro da literatura com os dados retirados dos relatórios, expressos nas categorias.

Todos os noventa e sete artigos aprovados no II Seminário Nacional de Agroecologia (SNEA) Resistências e Lutas pela Democracia e publicados na Revista Cadernos de Agroecologia (v. 12, n. 1) foram analisados, a partir da perspectiva da análise de conteúdo, construída por Bardin $(2004$, p. 63). O SNEA é um evento de referência para educação em agroecologia em nível nacional. O seu objetivo central é identificar, sistematizar, refletir e articular experiências de educação em agroecologia. A ideia deste seminário é promover o aprendizado mútuo e a identificação e ressignificação dos referenciais que orientam experiências concretas de Educação em Agroecologia (SNEA, 2017, p. 3-4).

A partir da leitura dos dados coletados e de um estudo do campo teórico proposto, foi construída a seguinte hipótese para a técnica de análise de conteúdo aplicada aos artigos publicados no II SNEA: A produção científica do II SNEA foi coerente com os princípios e diretrizes para Educação em Agroecologia disseminados pela ABA. O corpo legal da Constituição Federal Brasileira possibilitou que, em 1996, fosse publicada a nova Lei de Diretrizes e Bases da Educação Nacional (LDB - Lei no 9.394/96), que destacou em apenas um artigo a educação rural como garantia à população camponesa. Dessa forma, a referida lei, no artigo 28, apregoa que "[...] na oferta da educação básica rural, os sistemas de ensino promoverão as adaptações necessárias para sua adequação às peculiaridades da vida rural e de cada região [...]". Os dispositivos seguem no sentido 
de elaborar o currículo e a metodologia conforme as necessidades e os interesses dos alunos, assim como a adequação do calendário escolar ao contexto agrícola (Brasil, 1996); portanto, esses princípios e diretrizes da Educação em Agroecologia não prejudicam a LDB, pelo contrário, as suas adaptações ocasionam melhorias no ensino-aprendizagem de acordo com a realidade de cada região.

Com essa hipótese estabelecida, conforme mostra a Tabela 1, foram definidas as seguintes categorias e subcategorias, com seus respectivos códigos:

- Categorias:

- Princípio da Vida (1): É na natureza onde se reproduzem e se realizam todas as formas de vida, inclusive a dos seres humanos. Esta, portanto, deve ser respeitada integralmente na sua existência e na manutenção e regeneração de seus ciclos vitais, estruturas, funções e processos evolutivos (Aba-Agroecologia, 2013, p. 07).

- Princípio da Diversidade (2): O princípio da diversidade se contrapõe às concepções totalizadoras, homogêneas, padronizadoras, universais e excludentes presentes na educação. A diversidade deve ser reconhecida nos diferentes ecossistemas, agroecossistemas e paisagens, na riqueza de bens naturais, nas distintas práticas sociais, saberes (locais e acadêmicos), valores, cultura e formas de organização social e produtiva que determinam a relação dos seres humanos com a natureza (Aba-Agroecologia, 2013, p. 08).

- Princípio da Complexidade (3): A realidade é complexa e requer um pensamento também complexo. Desenvolver um pensamento complexo implica fugir da simplificação,
TABELA 1 - Síntese das categorias e subcategorias elaboradas no âmbito dos Grupos de Trabalho realizados no I Seminário de Educação em Agroecologia.

\begin{tabular}{|c|c|}
\hline \multirow{6}{*}{ Princípio da Vida -1} & Valorização da Vida - 1.1 \\
\hline & Sustentabilidade -1.2 \\
\hline & Processos Comunitários - 1.3 \\
\hline & Culturas Locais - 1.4 \\
\hline & Ecologia e Manejo - 1.5 \\
\hline & Economia Ecológica e Solidária - 1.6 \\
\hline \multirow{5}{*}{$\begin{array}{c}\text { Princípio da } \\
\text { Diversidade - } 2\end{array}$} & Territórios - 2.1 \\
\hline & Povos Tradicionais -2.2 \\
\hline & Saberes Ecológicos - 2.3 \\
\hline & Identidades Culturais - 2.4 \\
\hline & Mulheres - 2.5 \\
\hline \multirow{6}{*}{$\begin{array}{c}\text { Princípio da } \\
\text { Complexidade }-3\end{array}$} & Abordagem Holística - 3.1 \\
\hline & Práticas Agroecológicas - 3.2 \\
\hline & Extensão-Ensino-Pesquisa - 3.3 \\
\hline & Participação - 3.4 \\
\hline & Formação Continuada - 3.5 \\
\hline & Propor-agir - 3.6 \\
\hline \multirow{6}{*}{$\begin{array}{c}\text { Princípio da } \\
\text { Transformação }-4\end{array}$} & Emancipação - 4.1 \\
\hline & Formação - 4.2 \\
\hline & Empoderamento - 4.3 \\
\hline & Segurança Alimentar - 4.4 \\
\hline & Combate à Desigualdade - 4.5 \\
\hline & Formação Contextualizada - 4.6 \\
\hline
\end{tabular}

FONTE: Cadernos de Agroecologia - Anais do II SNEA. Elaborado pelos autores.

da fragmentação, da compartimentação, da hiperespecialização, do dualismo, da certeza e do reducionismo, colocando em prática a religação dos saberes, numa perspectiva transdisciplinar (Aba-Agroecologia, 2013, p. 09).

- Princípio da Transformação (4): A educação deve ser tomada como uma ferramenta de conscientização e libertação das estruturas ideológicas de dominação que sustentam a sociedade hegemônica, para formar profissionais críticos/as e criativos/as, com 
capacidades para compreender e atuar com autonomia para a promoção da vida e da sustentabilidade do planeta (Aba-Agroecologia, 2013, p. 12).

\section{Subcategorias:}

Valorização da Vida (1.1), Sustentabilidade (1.2), Processos Comunitários (1.3), Culturas Locais (1.4), Ecologia e Manejo (1.5), Economia Ecológica e Solidária (1.6), Territórios (2.1), Povos Tradicionais (2.2), Saberes Ecológicos (2.3), Identidades Culturais (2.4), Mulheres (2.5), Abordagem Holística (3.1), Práticas Agroecológicas (3.2), Ex-
tensão-Ensino-Pesquisa (3.3), Participação (3.4), Formação Continuada (3.5), Propor-agir (3.6), Emancipação (4.1), Formação (4.2), Empoderamento (4.3), Segurança Alimentar (4.4), Combate à Desigualdade (4.5) e Formação Contextualizada (4.6).

Para melhor entendimento sobre como as categorias e subcategorias estão relacionadas com os princípios e diretrizes da agroecologia, defendidos pela Associação Brasileira de Agroecologia, foi construída a Tabela 2, para justificar a categorização defendida nesta pesquisa.

TABELA 2 - Categorias/Subcategorias e suas relações com os Princípios e Diretrizes da Educação em Agroecologia elaborados no I Seminário de Educação em Agroecologia.

\begin{tabular}{|c|c|c|}
\hline \multirow{5}{*}{ VIDA } & Valorização da Vida - 1.1 & $\begin{array}{l}\text { Cuidado e afetividade com a vida, considerando a sua otimização e } \\
\text { valorização (Aba-Agroecologia, 2013, p. 07). }\end{array}$ \\
\hline & Sustentabilidade - 1.2 & $\begin{array}{l}\text { Sustentabilidade nas dimensões ecológica, econômica, social, cultural, } \\
\text { política e ética (Aba-Agroecologia, 2013, p. 07). }\end{array}$ \\
\hline & Processos Comunitários - 1.3 & Processos endógenos, locais e comunitários (Aba-Agroecologia, 2013, p.07). \\
\hline & Culturas Locais - 1.4 & $\begin{array}{l}\text { Valorização e garantia à livre reprodução das sementes e raças locais } \\
\text { de animais, reconhecendo-os como patrimônio da humanidade (Aba- } \\
\text { Agroecologia, 2013, p. 07). }\end{array}$ \\
\hline & Economia Ecológica e Solidária -1.6 & Economia ecológica e solidária (Aba-Agroecologia, 2013, p.08). \\
\hline \multirow{4}{*}{ DIVERSIDADE } & Territórios - 2.1 & $\begin{array}{l}\text { Reconhecimento do território onde estão inseridos, considerando toda a sua } \\
\text { complexidade e diversidade ecossistêmica e social e como espaço em disputa } \\
\text { e conflito entre os diferentes setores socioeconômicos (Aba-Agroecologia, } \\
2013 \text {, p.08). }\end{array}$ \\
\hline & Saberes Ecológicos - 2.3 & $\begin{array}{l}\text { Valores e conhecimentos dos povos e comunidades tradicionais como fonte } \\
\text { de ensinamentos ecológicos e culturais essenciais para a conservação da } \\
\text { biodiversidade e a construção da sustentabilidade (Aba-Agroecologia, 2013, } \\
\text { p. 09). }\end{array}$ \\
\hline & Identidades Culturais - 2.4 & $\begin{array}{l}\text { Diferentes movimentos e organizações sociais, considerando as questões } \\
\text { de gênero, diversidade sexual, étnica e geracional e reafirmando o território } \\
\text { como espaço de identidades e de culturas (Aba-Agroecologia, 2013, p. 09). }\end{array}$ \\
\hline & Mulheres - 2.5 & $\begin{array}{l}\text { Reconhecimento das especificidades das mulheres trabalhadoras, suas } \\
\text { formas de interpretar e atuar sobre a realidade e suas formas de organização } \\
\text { (Aba-Agroecologia, 2013, p. 09). }\end{array}$ \\
\hline
\end{tabular}


Abordagem Holística - 3.1

Práticas Agroecológicas - 3.2

Extensão-Ensino-Pesquisa $\mathbf{-} \mathbf{3 . 3}$

COMPLEXIDADE

Participação - 3.4

Formação Continuada - 3.5

Propor-agir - 3.6

Emancipação - 4.1

TRANSFORMAÇÃO
Desenvolvimento de análises da realidade a partir de uma abordagem sistêmica e holística (Aba-Agroecologia, 2013, p. 10).

Valorização, sistematização e socialização participativa de processos e práticas agroecológicas, valorizando os conhecimentos, as culturas populares e as suas formas de expressão (Aba-Agroecologia, 2013, p. 10).

Indissociabilidade entre extensão-ensino-pesquisa (Aba-Agroecologia, 2013, p. 10).

Relevância das pessoas, da comunidade e das relações sociais na construção do conhecimento agroecológico. Leitura crítica da realidade e adoção de instrumentos metodológicos participativos. Construção participativa dos Projetos Político-Pedagógicos, considerando as especificidades locais, com a participação da comunidade e dos movimentos sociais (Aba-Agroecologia, 2013, p. 10).

Formação inicial e continuada em Agroecologia para educadores/as e técnicos/as administrativos/as (Aba-Agroecologia, 2013, p. 11).

Superação da dicotomia entre trabalho manual e intelectual, vinculando o mundo do trabalho e a prática social. Superação da dicotomia entre teoriaprática para contribuir para conhecer-compreender e propor-agir (AbaAgroecologia, 2013, p. 11).

Promoção de práticas emancipatórias, visando à autonomia e ao protagonismo dos sujeitos na construção de relações sociais justas e solidárias e da consciência planetária (Aba-Agroecologia, 2013, p. 11).

Preparação de profissionais para atuar segundo os princípios da Economia solidária popular e ecológica, baseada na cooperação, na reciprocidade e nos valores das culturas locais. Prática pedagógica comprometida com a transformação social, visando formar profissionais que coloquem os seus conhecimentos a serviço das classes populares e da conservação da natureza (Aba-Agroecologia, 2013, p. 12).

Processos educativos voltados para a compreensão, o fortalecimento e o empoderamento das coletividades que atuam na transformação da realidade agrária e agrícola do país (Aba-Agroecologia, 2013, p. 12).

Promoção da soberania e segurança alimentar e nutricional e saúde integral, interligando produção e consumo de produtos ecológicos (Aba-Agroecologia, 2013, p. 12).

Atuação crítica sobre todas as formas de dominação e desigualdades sociais, particularmente sobre aquelas de gênero, raça, etnia, diversidade sexual e geração (Aba-Agroecologia, 2013, p. 13).

Formação referenciada na realidade, tomando a vivência das comunidades como conteúdos problematizadores para o processo de ensino aprendizagem (Aba-Agroecologia, 2013, p. 13).

FONTE: Cadernos de Agroecologia - Anais do II SNEA. Elaborado pelos autores. 


\section{Diálogo com os princípios e diretrizes da educação em agroecologia}

De acordo com Aguiar et al. (2016, p. 15), no I Seminário Nacional de Educação em Agroecologia (SNEA) foram estabelecidos quatro princípios e diretrizes fundamentais para a Educação em Agroecologia: Princípio da Vida, Princípio da Complexidade, Princípio da Diversidade e Princípio da Transformação. Os mesmos autores consideram que princípios e diretrizes servem para se colocar em prática um determinado propósito que, por sua vez, necessita de caminhos e orientações.

O II Seminário Nacional de Educação em Agroecologia (SNEA) foi realizado em Seropédica-RJ, de 25 a 27 de outubro de 2016, para debater o tema "Educação em Agroecologia: resistências e lutas pela democracia". Este tema reflete os acúmulos e aprendizados desde o I SNEA e a preocupação com as ameaças de desmonte institucionais que colocam em risco os avanços duramente conquistados pela sociedade brasileira em seu processo de democratização, com a participação de 420 profissionais da extensão, ensino e pesquisa, da comunicação, estudantes dos diferentes níveis e modalidades de ensino, agricultores e agricultoras, povos e comunidades tradicionais, jovens, mulheres e homens de todo o Brasil.

O II SNEA promoveu reflexões e debates, se propôs a refletir e aprofundar análises deste cenário para que se pudesse acolher diferentes trajetórias de experiências educativas, compreender as contradições inerentes e visualizar caminhos comuns, na diversidade de grupos, redes e movimentos que constroem a Educação em Agroecologia no Brasil, dentro e fora das instituições de ensino, no qual foram socializadas e debatidas 170 experiências de Educação em Agroecologia, articuladas a partir de eixos temáticos sobre a construção do conhecimento agroecológico, a formação do profissional em agroecologia e a questão agrária e agroecologia. Estas experiências são fruto do acúmulo histórico protagonizado por educadores/as, estudantes e pelos movimentos sociais do campo.

É importante ressaltar que, por meio da metodologia aplicada, foi possível detectar múltiplas categorias e subcategorias nos artigos analisados. Os princípios agroecológicos estão, desta forma, diversa e complexamente representados na produção científica do II Seminário Nacional de Educação em Agroecologia. Em geral, dois ou três princípios estão presentes, significativamente, em cada artigo.

Ao todo foram aprovados 97 (noventa e sete) artigos no II SNEA, como mostra a Figura 1. Dessa quantidade, $44 \%$ dos artigos estão relacionados com o Princípio da Vida, 39\% com o Princípio da Diversidade, 67\% com o Princípio da Complexidade e $54 \%$ com o Princípio da Transformação. Destaque para os temas ligados aos princípios da complexidade e da transformação, que tiveram um maior número de trabalhos aprovados.

Os princípios da vida, da diversidade, da complexidade e da transformação propostos no I SNEA para a Educação em Agroecologia vêm sendo reforçados e colocados em prática nestas experiências publicadas nos anais do II SNEA.

É importante reconhecer que essas experiências possuíam diferentes níveis de percepção sobre o papel da Agroecologia e sobre o significado da sustentabilidade na produção e sua relação com a agricultura familiar e que os princípios e as diretrizes para a educação deveriam ser construídos a partir da socialização destas percepções e da construção das experiências educativas na sua prática cotidiana (Aba-Agroecologia, 2013, p. 10). 


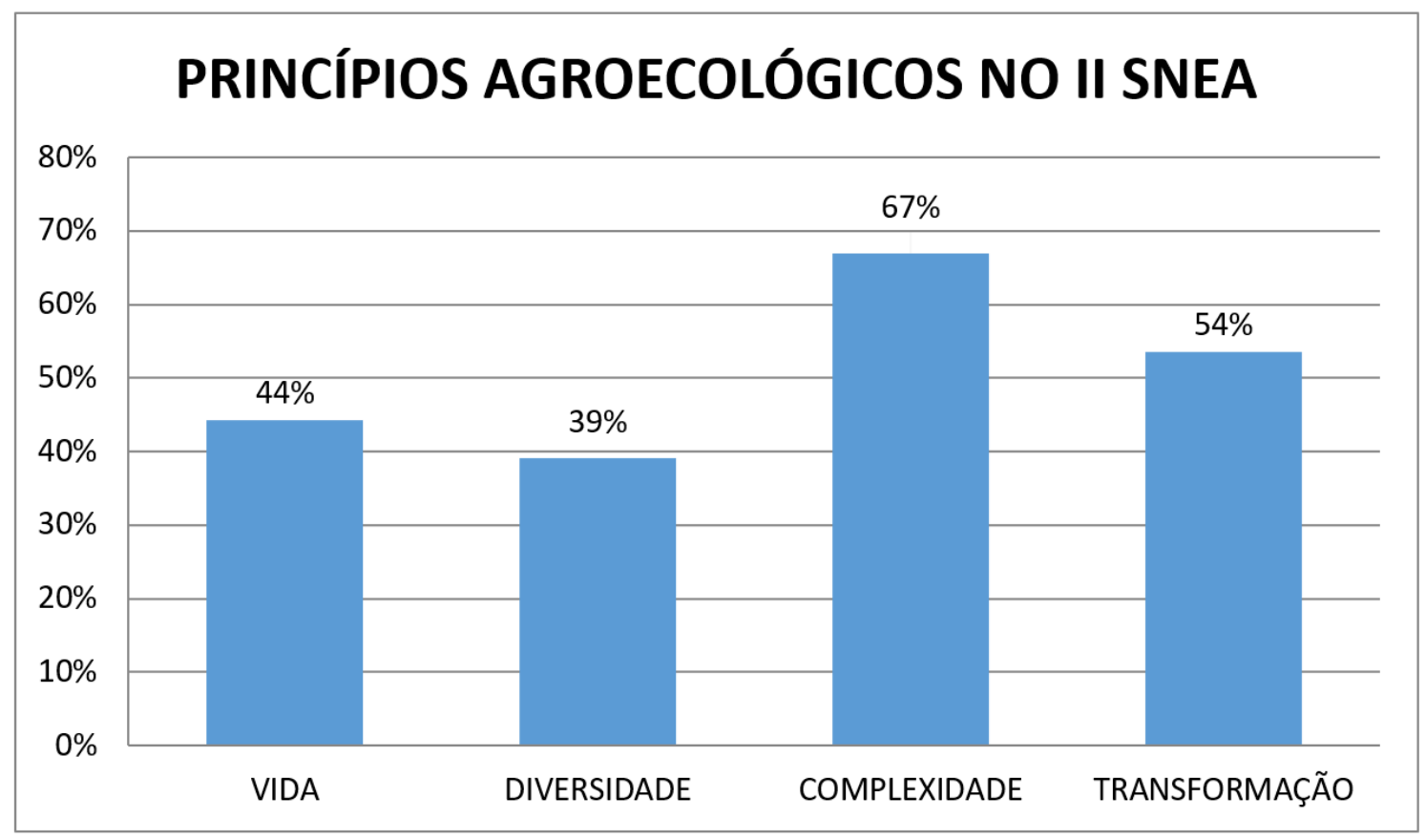

FIGURA 1 - Princípios Agroecológicos no II SNEA.

FONTE: Cadernos de Agroecologia - Anais do II SNEA. Elaborado pelos autores.

É relevante destacar a extensa presença de metodologias participativas nestas publicações. Muitos trabalhos estão relacionados à interação de diversos atores e, por meio de diálogos e ações de formação, os processos formativos também apareceram significativamente nas referidas publicações.

$\mathrm{Na}$ categoria Princípio da Vida, como apresentado na Figura 2, vale destacar as subcategorias com maior número de artigos aprovados no II SNEA, sendo elas: sustentabilidade (1.2), processos comunitários (1.3) e ecologia e manejo (1.5), com 11 (onze) artigos aprovados, enquanto as subcategorias com o menor número de trabalhos aprovados foram: valorização da vida (1.1), culturas locais (1.4), am- bas com 04 (quatro) artigos aprovados, enquanto economia ecológica e solidária (1.6) teve 06 (seis) trabalhos aprovados.

A categoria Princípio da Vida teve um total de $44 \%$ dos artigos aprovados no II SNEA, sendo distribuídos nas suas seis subcategorias. Destaque para as temáticas sustentabilidade, processos comunitários e ecologia e manejo, com o maior número publicações; essa maior demanda de publicações nessas áreas está relacionada com uma maior integração dos participantes com essas temáticas.

Entretanto, outro importante aspecto a ser observado foi a pouca quantidade de artigos submetidos às subcategorias valorização da vida e 


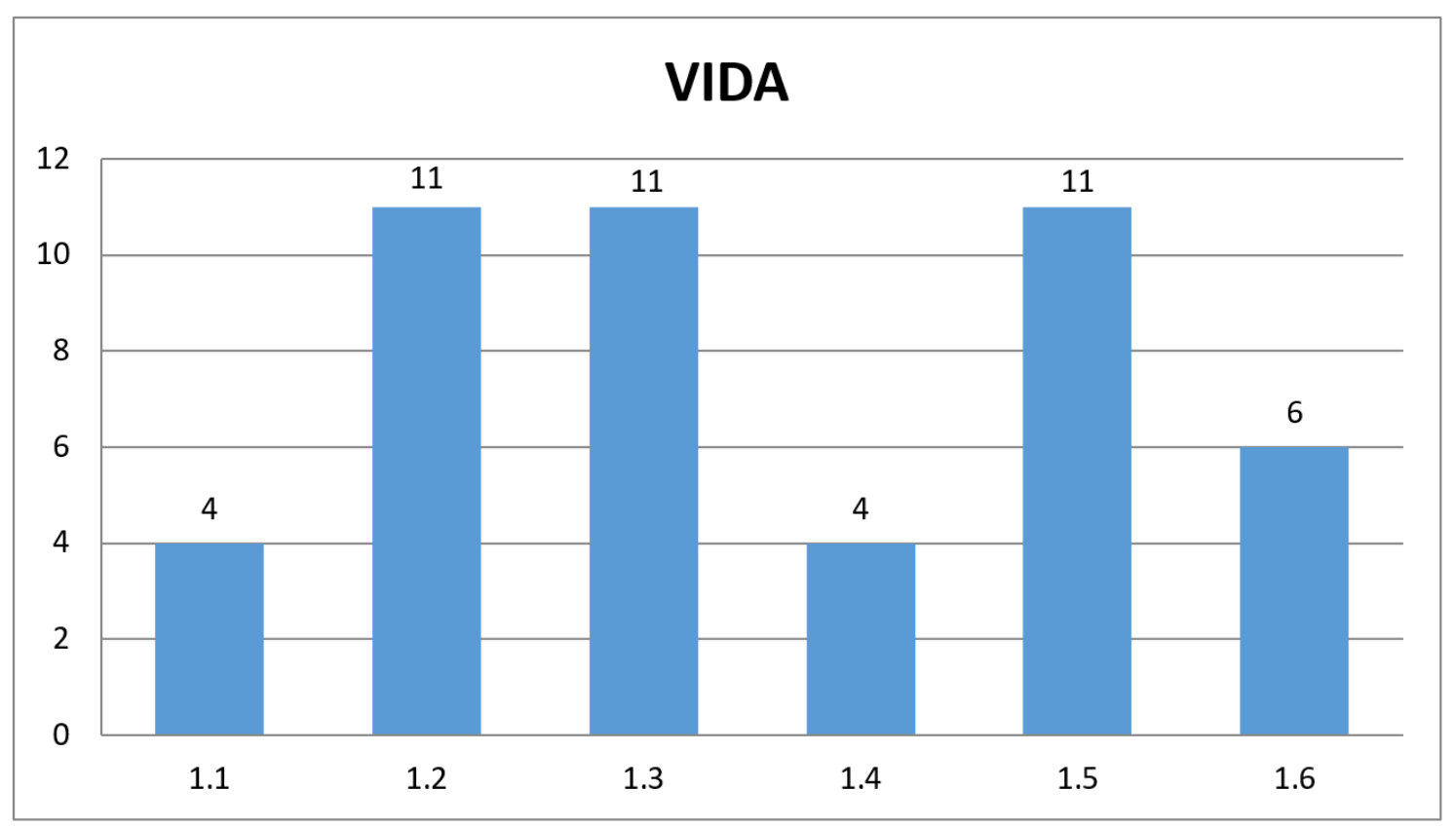

FIGURA 2 - Princípio da Vida.

FONTE: Cadernos de Agroecologia - Anais do II SNEA. Elaborado pelos autores.

culturas locais; pela sua importância e relevância dentro da agroecologia, é importante intensificar os estudos nessas áreas. É uma sugestão para os próximos encontros e consequentemente para o desenvolvimento de novas pesquisas.

Em relação ao Princípio da Diversidade, como mostra a Figura 3, chama atenção o pouco número de trabalhos aprovados na subcategoria relacionada à temática das mulheres (2.5), com apenas 01 (um) artigo aprovado, enquanto a subcategoria saberes ecológicos (2.3) teve um maior número de trabalhos aprovados, com um total de 19 (dezenove), a temática territórios (2.1) teve 13 (treze) artigos aprovados, e as subcategorias povos tradicionais (2.2) e identidades culturais (2.4) tiveram 9 (nove) trabalhos aprovados.
O Princípio da Diversidade, com apenas 39\% dos artigos aprovados no II SNEA, foi a categoria com menor número de publicações, como também com a menor quantidade de subcategorias, apenas cinco. Vale destacar a importância dessas temáticas para o processo de formação em Educação em Agroecologia, com destaque positivo para a subcategoria saberes ecológicos, com o maior número de publicações; os relatos na temática saberes ecológicos trazem um olhar para os valores e conhecimentos dos povos e comunidades tradicionais como fonte de ensinamentos ecológicos e culturais essenciais para a conservação da biodiversidade e a construção da sustentabilidade.

A temática mulheres, com apenas um artigo aprovado, ficou aquém do que se esperava em ter- 


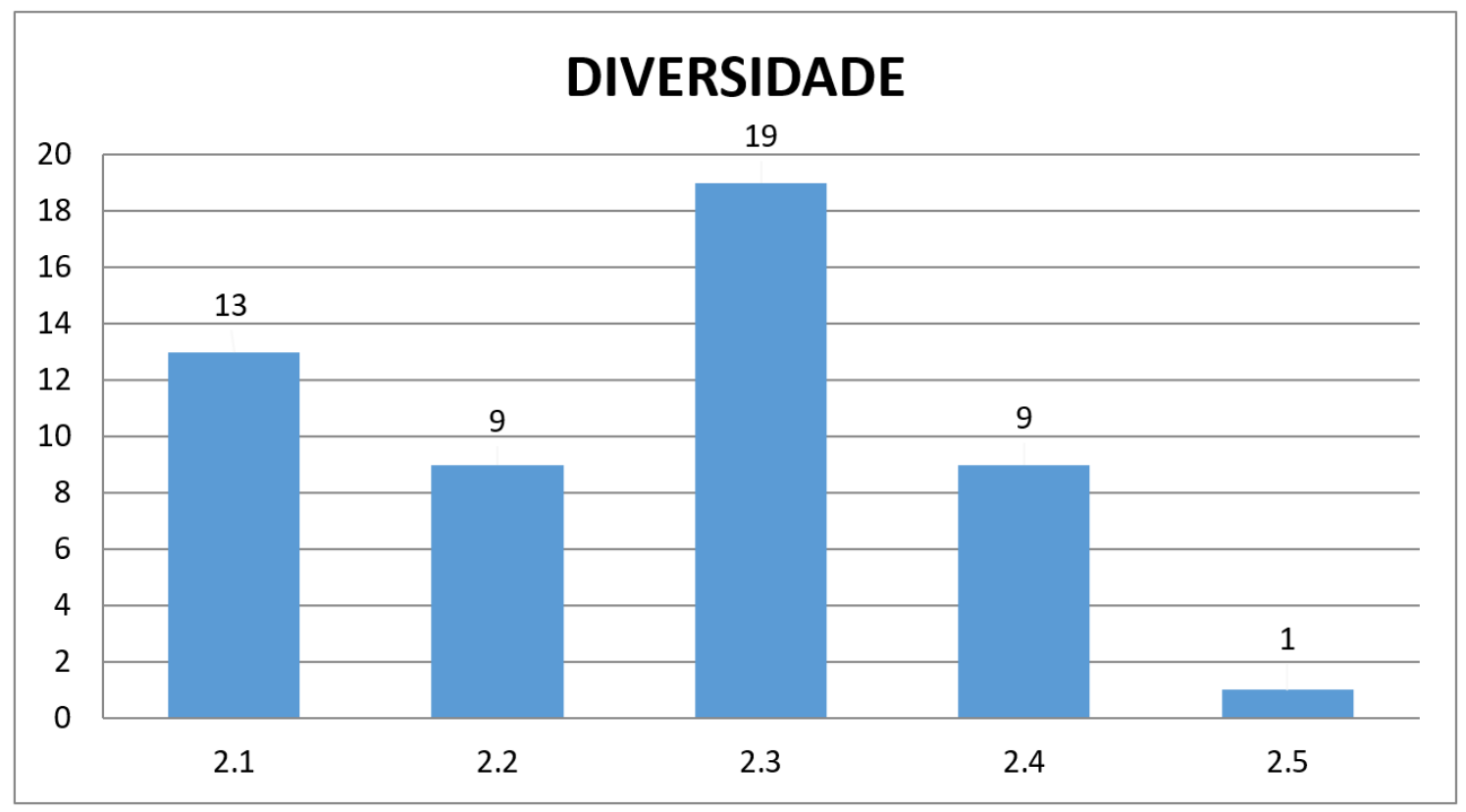

FIGURA 3 - Princípio da Diversidade.

FONTE: Cadernos de Agroecologia - Anais do II SNEA. Elaborado pelos autores.

mos de publicações. Vale destacar a importância desse tema nos espaços estratégicos de formação, articulação e produção do conhecimento e das práticas agroecológicas realizadas pelas mulheres, integrando a abordagem de gênero e feminismo.

Como bem observa Santos (2005, p. 32), as mulheres constituem um grupo diferenciado, interagindo de múltiplas formas e em diferentes níveis em função dos contextos histórico, social, econômico e ambiental em que são socializadas.

A superação das formas de subordinação feminina tem sido objeto de ação política dos movimentos de mulheres e da auto-organização de mulheres em movimentos sociais mistos (Butto, 2011, p. 19). Nesse caminho, elas mobilizam recursos materiais e simbólicos para realizar ações coletivas, conquistando espaços próprios e reconhecimento político (Pimenta, 2006, p. 161).

Ao analisarmos o Princípio da Complexidade, de acordo com a Figura 4, a subcategoria participação (3.4) teve um alto número de trabalhos enviados e aprovados, sendo ao todo 25 (vinte e cinco), com destaque negativo para as subcategorias formação continuada (3.5) e propor-agir (3.6), com apenas 08 (oito) artigos aprovados, e para as subcategorias abordagem holística (3.1) com 11 (onze) artigos aprovados, seguidas de práticas agroecológicas (3.2) com 15 (quinze) artigos aprovados e extensão-ensino-pesquisa (3.3) com 18 (dezoito) trabalhos aprovados no II SNEA. 


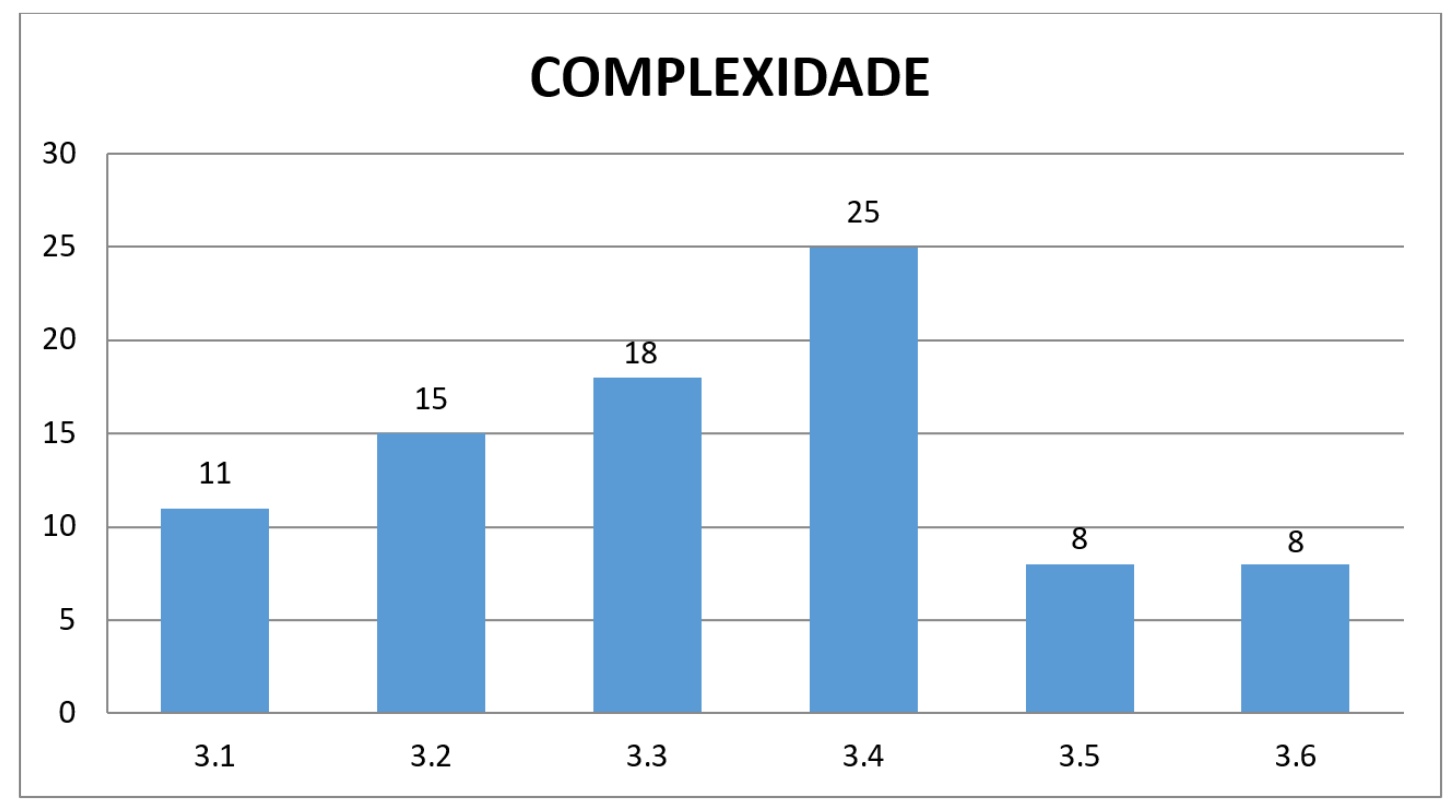

FIGURA 4 - Princípio da Complexidade.

FONTE: Cadernos de Agroecologia - Anais do II SNEA. Elaborado pelos autores.

A categoria Princípio da Complexidade teve o maior número de produções científicas, com $67 \%$ dos artigos aprovados no II SNEA, como também um maior número de artigos por subcategorias. Isso mostra a importância desse princípio para o processo de construção do conhecimento agroecológico, tendo como elementos essenciais a visão holística e sistêmica da ciência, a imersão nas relações sociais comunitárias, a construção social dos projetos atores, o diálogo de saberes, os princípios ecológicos de agricultura, o mercado embebido nas relações sociais, o método participativo e a transição agroecológica e participação.

Nesse sentido, a Associação Brasileira de Agroecologia - ABA, principal espaço que congrega os estudiosos da Agroecologia no Brasil, tem como um dos seus objetivos a busca do aprimora- mento dos métodos que promovam uma construção coletiva de conhecimento entre organizações que trabalham com o ensino, a pesquisa na agricultura e na extensão rural (ABA-Agroecologia, 2007, p. 15).

No Princípio da Transformação, como mostra a Figura 5, destaque para a subcategoria formação (4.2), com 23 (vinte e três) artigos aprovados, enquanto o destaque negativo em relação ao número de trabalhos aprovados foi a subcategoria combate à desigualdade (4.5), com apenas 02 (dois) artigos aprovados. A temática emancipação (4.1) teve 05 (cinco) artigos aprovados; empoderamento (4.3) com 04 (quatro) artigos aprovados, segurança alimentar (4.4) com 10 (dez) artigos aprovados e formação contextualizada (4.6) com 16 (dezesseis) artigos aprovados no II SNEA complementam o quadro. 


\section{TRANSFORMAÇÃO}

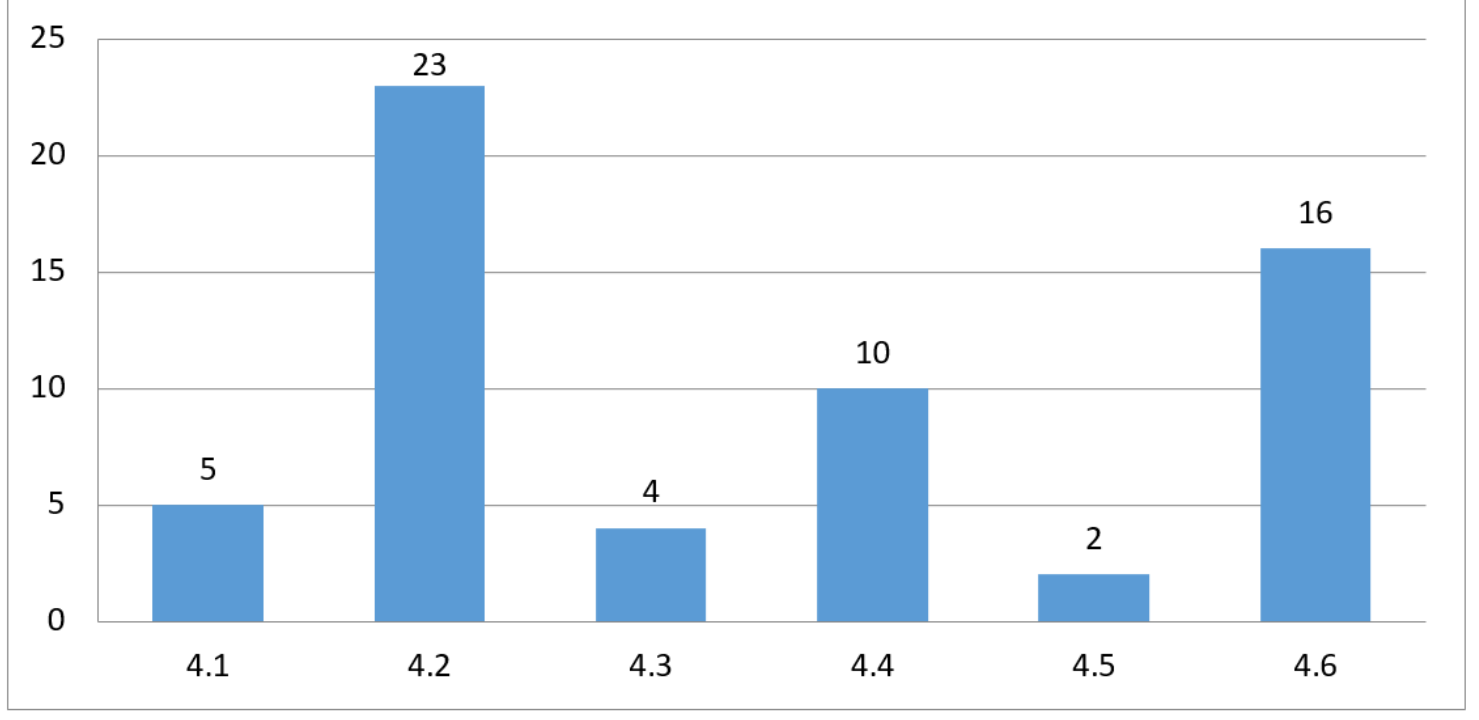

FIGURA 5 - Princípio da Transformação.

FONTE: Cadernos de Agroecologia - Anais do II SNEA. Elaborado pelos autores.

A categoria Princípio da Transformação teve o segundo maior número de trabalhos aprovados no II SNEA, com 54\%, com destaque para a subcategoria formação, com a maior quantidade de publicações. Vale salientar a importância desse tema para a preparação de profissionais para atuar segundo os princípios da economia solidária popular e ecológica, baseada na cooperação, na reciprocidade e nos valores das culturas locais, nas práticas pedagógicas comprometidas com a transformação social, visando formar profissionais que coloquem os seus conhecimentos a serviço das classes populares e da conservação da natureza.

Apesar de a ideia ser internacionalizada, vem ganhando no Brasil traços de sua cultura à medida que as experiências de formação por alternância começam a se expressar, principalmente no campo da educação agrícola (Begnami, 2004, p. 08). Muitos cursos de Agroecologia optam por essa metodologia de formação e essa característica consolida a dimensão do diálogo entre os saberes populares e acadêmicos, sendo a amálgama de uma grande força da construção do conhecimento agroecológico.

A subcategoria combate à desigualdade teve a menor quantidade de trabalhos aprovados; as discussões em torno do combate à desigualdade social são praticamente despercebidas e estão fora das problematizações dos pesquisadores em Educação em Agroecologia. O tema combate à desigualdade abordou nos artigos uma atuação crítica sobre todas 
as formas de dominação e desigualdades sociais, particularmente sobre aquelas de gênero, raça, etnia, diversidade sexual e geração. Paulo Freire (1987, p. 95) já assegurava que o ato educativo não é neutro e que o educador deve assumir seu compromisso com o povo, com a redução das desigualdades, com a justiça social e contra todas as formas de opressão, exclusão e ações que atentem contra a vida.

\section{Considerações finais}

O Seminário Nacional de Educação em Agroecologia representa uma boa oportunidade de apresentação e discussão de temas relacionados aos princípios e às diretrizes da Educação em Agroecologia defendidos pela Associação Brasileira de Agroecologia. O II SNEA, com seus 97 artigos apresentados, trouxe uma significativa abordagem no contexto de suas áreas de pesquisa e aplicação.

A Educação em Agroecologia deve se dar no contexto territorial em que se encontra, com seus atores debatendo as relações de poder e os conflitos, devendo-se contribuir para fortalecer a organização social e a construção de um projeto popular que tenha como centralidade a luta pela terra em consonância com os princípios da agroecologia e o bem viver. Uma educação que valoriza a pesquisa e o trabalho como princípios educativos, favorecendo uma perspectiva crítica e politécnica da formação profissional.

É importante reconhecer, em qualquer evento ou publicação relacionado à Educação em Agroecologia, a necessidade da abordagem dos temas fundamentais para sua construção, como a luta pela terra, a reforma agrária, a defesa dos bens comuns e dos territórios, a indissociabilidade da extensão, ensino e pesquisa, a transdiciplinaridade, $o$ feminismo, a construção do conhecimento e o diálogo de saberes, as juventudes, o diálogo intercultural, a sexualidade, as políticas públicas, a segurança e a soberania alimentar, a saúde e a economia solidária.

De fato, é percebido que os princípios da vida, da diversidade, da complexidade e da transformação, propostos no SNEA para a Educação em Agroecologia, vêm sendo reforçados e colocados em prática nestas experiências.

\section{Agradecimentos}

Agradecemos em especial ao Programa de Pós-Graduação em Agroecologia e Desenvolvimento Territorial (PPGADT), em nível Doutorado profissional, da Universidade Federal do Vale do São Francisco (UNIVASF), e a todos que contribuíram direta ou indiretamente para a publicação deste artigo. 


\section{Referências}

ABA-Agroecologia - Associação Brasileira de Agroecologia. Construção do conhecimento agroecológico. Brasília: ABA, 2007.

ABA-Agroecologia - Associação Brasileira de Agroecologia. Anais do I Seminário Nacional de Educação em Agroecologia. Construindo princípios e diretrizes. Pernambuco: NAC - UFRPE, 2013.

Aguiar, M. V. A.; Mattos, J. L. S.; Lima, J. R. T.; Figueiredo, M. A. B.; Silva, J. N.; Caporal, F. R. Princípios e diretrizes da Educação em Agroecologia. Revista Cadernos de Agroecologia, Recife, 11(1), 2016.

Almeida, S. G.; Petersen, P.; Cordeiro, A. Crise socioambiental e conversão agroecológica da agricultura brasileira. Rio de Janeiro: ASPTA - Assessoria e Serviços de Agricultura Alternativa, 2001.

Almeida, S. R. M. Agroecologia, o romance da Agronomia. Cruz das Almas: Ed. do autor, 2013. 25 p.

Altieri, M. A. Agroecologia: bases científicas para uma agricultura sustentável. Guaíba: Agropecuária; AS-PTA, 2002. 592 p.

Bardin, L. Análise de conteúdo. Lisboa: Edições 70, 2004. $118 \mathrm{p}$.

Begnami, J. B. Uma geografia da Pedagogia da Alternância no Brasil. Documentos Pedagógicos. UNEFAB, 2004.

Brasil. Ministério da Educação. Lei n. 9.394/96, de 20 de dezembro de 1996. Lei de Diretrizes e Bases da Educação Nacional. Brasília, 1996.

Butto, A. Políticas para mulheres rurais: autonomia e cidadania. In: Butto, A.; Dantas, I. (Org.). Autonomia e Cidadania: política de organização produtiva para as mulheres no meio rural. 1. ed. Brasília: MDA, 2011. p. 11-36.

Caporal, F. R. Agroecologia: uma nova ciência para apoiar a transição a agriculturas mais sustentáveis. In: Faleiro, F. G.; Farias Neto, A. L. de. Savanas: desafios e estratégias para o equilíbrio entre sociedade, agronegócio e recursos naturais. Planaltina-DF: Embrapa Cerrados, 2008. p. 895-929.
Carvalho, H. M. Na sombra da imaginação (3): o camponês e a superação de um destino medíocre. Curitiba, agosto de 2010.

Cooperfumos - Cooperativa Mista dos Fumicultores do Brasil. Caderno de Estudos: Geração de melhores condições de vida e sustentabilidade para agricultores familiares no Rio Grande do Sul. Santa Cruz do Sul, 2009.

Costabeber, J. A.; Moyano, E. Transição agroecológica e ação social coletiva. Agroecologia e Desenvolvimento Rural Sustentável, 1(4), 50-60, 2000.

Cotrim, D. S.; Dal Soglio, F. K. Construção do conhecimento agroecológico: problematizando o processo. Revista Brasileira de Agroecologia, 11, 257-271, 2016.

Duarte, V. P.; Rabelo, A. K. Fundamentos da educação em agroecologia. Cadernos de Agroecologia, [S.1.], 11(1), jun. 2016. 21 p. ISSN 2236-7934.

Freire, P. Pedagogia do oprimido. 17. ed. Rio de Janeiro: Paz e Terra, 1987. 187 p.

Gil, A. C. Métodos e técnicas de pesquisa social. 6. ed., 2. reimpr. São Paulo: Atlas, 2008.

Gliessman, S. R. Agroecologia: processos ecológicos em agricultura sustentável. 3. ed. Porto Alegre: Editora da Universidade - UFRGS, 2005.

Gliessman, S. R. Agroecologia: processos ecológicos em agricultura sustentável. Porto Alegre: Editora da Universidade - UFRGS, 2009. 653 p.

Guhur, D. M. P.; Toná, N. Agroecologia. In: Caldart, R. S.; Pereira, I. B.; Alentejano, P.; Frigotto, G. (Orgs.). Dicionário de Educação do Campo. Rio de Janeiro, São Paulo: Escola Politécnica de Saúde Joaquim Venâncio, Expressão Popular, 2012. p. 59-66.

Guzmán Casado, G. I.; González de Molina, M.; Sevilla Guzmán, E. (Coord.). Introducción a la Agroecología como desarrollo rural sostenible. Madrid: Ediciones Mundi-Prensa, 2000. 32 p. 
Lacey, H. A controvérsia sobre os transgênicos: questões científicas e éticas. São Paulo: Ideias e Letras, 2006.

Lacey, H. Pluralismo metodológico, incomensurabilidade e o status científico do conhecimento tradicional. Scientiae Studia, 10(3), 425-454, 2012.

Leff, E. Agroecologia e saber ambiental. Agroecologia e Desenvolvimento Rural Sustentável, 3(1), 36-51, 2001.

Machado, L. C. P. A dialética da Agroecologia: contribuições para um mundo com alimentos sem veneno. 1. ed. São Paulo: Expressão Popular, 2014.

Menegueli, H. O.; Ferrari, J. L.; Siqueira, H. M de; Lima, W. L. de; Amaral, A. A. do. Agroecologia brasileira no marco do plano nacional de agroecologia e produção orgânica: Cenário atual, Perspectivas e desafios. Enciclopédia Biosfera, 11(22), 29-45, 2015.

Molina, M. C.; Santos, C. A.; Michelotti, F.; Sousa, R. P. (Orgs.). Práticas contra-hegemônicas na formação dos profissionais das ciências agrárias: reflexões sobre agroecologia e educação do campo nos cursos do Pronera. Brasília: MDA, 2014. 292 p. (Série NEAD Debate; 22)

Morin, E. A organização (do objeto ao sistema). In: Morin, E. O método 1: a natureza da natureza. 2. ed. Porto Alegre: Sulina, 2005.
Morin, E. Introdução ao pensamento complexo. 5. ed. Lisboa: Instituto Piaget, 2008. 177 p.

Petersen, P. Agroecologia e políticas públicas na América Latina: o caso do Brasil. Agroecología, Múrcia/Espanha, 6, 63-74, 2012.

Pimenta, S. de O. C. Identidades em trajetórias: gênero e processos emancipatórios na reforma agrária. In: Woortmann, E. F.; Hedia, B.; Menashe, R. (Org.). Coletânea Margarida Alves sobre estudos rurais e gênero. Brasília: DF, 2006. p. 150-176.

Santos, B. S. Semear outras soluções. Os caminhos da biodiversidade e dos conhecimentos rivais. Rio de Janeiro: Civilização Brasileira, 2005. ANEXOS: Figura 1. Intercâmbio de mulheres assentadas em Itaperuna/RJ. Fonte: Arquivo Projeto de Pesquisa/Intervenção MST - UFRRJ.

Sevilla Guzmán, E. El despliegue de la sociología agraria hacia la Agroecología. Cuaderno Interdisciplinar de Desarrollo Sostenible, Fundación Cajamar, 10, 85-109, abr. 2013.

SNEA. Caderno de Agroecologia. Anais do II Seminário Nacional de Educação em Agroecologia - Resistências e Lutas pela Democracia. V. 12, n. 1. Seropédica (RJ). 2017. Disponível em: <https://aba-agroecologia.org.br/snea/>. 